Gut, 1989, 30, 195-200

\title{
Non-cryptosporidial diarrhoea in human immunodeficiency virus (HIV) infected patients
}

\author{
G M CONNOLLY, D SHANSON, D A HAWKINS, J N HARCOURT WEBSTER, \\ AND B G GAZZARD
}

From St Stephen's Hospital, London

SUMmaRY Thirty of 81 consecutive HIV antibody positive patients referred with non-cryptosporidial diarrhoea had no potential infectious cause; most had AIDS related complex rather than the full blown syndrome. Opportunistic infections with cytomegalovirus (CMV), mycobacterium avium-intracellulare (MAI), and herpes simplex virus (HSV), which allowed a diagnosis of AIDS to be made, were found in 19 patients and were the presenting features of AIDS in five. Other potential pathogenic species included entamoeba, giardia, campylobacter, and salmonella (without septicaemia). Cytomegalovirus infection was often accompanied by abdominal pain. Severe weight loss $(>10 \mathrm{~kg})$ at presentation was found in patients with CMV infection and MAI. Bloody diarrhoea was confined to the group with HSV procitis. Malignant causes of diarrhoea were rare. Two patients developed a squamous carcinoma of the anorectal margin and one a non-Hodgkin's lymphoma. In only two of 12 patients who had Kaposi's sarcoma was this considered as a cause of diarrhoea. Rigid sigmoidoscopy showed macroscopic abnormalities in over a third (32) of the 81 patients with noncryptosporidial diarrhoea. Most commonly this was severe inflammation (17) or discrete ulceration (four) [three of whom had CMV colitis]. Kaposi's sarcoma was identified in 11 patients. Non-specific inflammation was seen histologically in 40 of the 60 patients with no sigmoidoscopic inflammatory changes. Barium enema only revealed an abnormality in a minority of the patients and a colonoscopy only revealed information additional to rigid sigmoidoscopy in two patients - one with CMV ulcers in the transverse colon and the other with evidence of Kaposi's sarcoma not seen in the rectum. Ten patients had a rectal biopsy examined by electron microscopy as no infective cause of diarrhoea was uncovered. In four of these microtubular structures which are commonly seen in viral infections were found and two had prelymphomatous changes and in one of these frank lymphoma has developed. We recommend multiple stool analysis, sigmoidoscopy and rectal biopsy as the initial investigations in these patients reserving tests of malabsorption, colonoscopy, and barium enema for the small number of more difficult cases.

The cellular immune deficiency caused by the human immunodeficiency virus (HIV) predisposes patients to a number of infections causing diarrhoea including cryptosporidium, ${ }^{1}$ salmonella, ${ }^{2}$ and mycobacterium avium intracellulare (MAI). ${ }^{3}$ In addition the commonest group of patients with the acquired immunodeficiency syndrome (AIDS) in Britain at present are homosexuals who often acquire organisms venereally which may cause diarrhoea

Address for correspondence: B G Gazzard, FRCP, St Stephen's Hospital, Fulham Road, London SW10 9TH.

Accepted for publication 21 July 1988. including giardia, chlamydia, and entamoeba species. ${ }^{4}$

About $70 \%$ of our patients with AIDS related complex (ARC) complain of intermittent diarrhoea, and $50 \%$ of AIDS patients complain of a more persistent looseness of their bowels. There is no evidence that the epidemic of AIDS in the United Kingdom is slowing, and even if AIDS remains confined to the presently perceived high risk groups, all gastroenterologists will become familiar with this problem.

The present study was designed to assess the 
causes, treatment, value of investigations, and clinical features of a consecutive group of patients with persistent diarrhoea who were ill with HIV infection.

\section{Methods}

PATIENTS

Of the 1250 patients at present being followed at $\mathrm{St}$ Stephen's Hospital because of an HIV antibody positive blood test, 107 consecutive patients were referred between August 1986 and December 1987 with persistent diarrhoea and symptoms of AIDS (71) or ARC (36). AIDS was defined by the CDC classification. ${ }^{5}$ AIDS related complex patients included those with greater than $10 \%$ loss of body weight, those with buccal candidiasis and those with persistent diarrhoea of greater than one month's duration. The HIV antibody status of the patients was initially screened by an ELISA test ${ }^{6}$ and confirmed in all cases by at least two other methods. ${ }^{7}$ All patients had at least three liquid bowel actions a day persisting for more than a month. Six samples from each patient were sent for bacteriological investigation and of these 26 had cryptosporidial diarrhoea and formed part of our report of clinical experience with this condition. ${ }^{1}$ The remaining 81 patients are the subject of this report and were admitted to hospital where daily stool volumes were measured, six further stool samples were analysed and a colonoscopy carried out. All patients also had a rigid sigmoidoscopy at which at least two rectal biopsies were done. Thirty six patients agreed to have a barium enema.

The last 10 patients in whom no microbiological cause of diarrhoea was uncovered also had detailed electron microscopic studies of rectal biopsies.

\section{MICROBIOLOGICAL METHODS}

All stools were cultured routinely, and microscoped for ova cysts and parasites. They were stained using a modified Ziehl-Nielsen stain with concentration for cryptosporidium. $^{8}$ When acid fast bacilli were detected the faeces were further processed for culture and inoculated onto a Lowenstein-Jensen slope and also onto Kirchner medium ${ }^{9}$ and examined weekly for 10 weeks. Mycobacterium avium intracellulare was considered to be a possible cause of diarrhoea irrespective of histological changes if the organism was isolated from the stool.

\section{HISTOLOGY}

Rectal and duodenal biopsies were stained with haemotoxylin and eosin. A careful search of the whole biopsy specimen was made for mycobacteria using a Ziehl-Nielsen stain. Cytomegalovirus colitis
Table 1 Causes of diarrhoea in 81 HIV antibody positive patients

\begin{tabular}{clcc}
\hline & & $A R C$ & $A I D S$ \\
\hline Opportunists (as & $\mathrm{CMV}^{1}$ & - & $6(2)^{*}$ \\
defined by the & $\mathrm{MAI}^{2}$ & - & $10(3)^{*}$ \\
CDC $^{\prime}$ ) & $\mathrm{HSV}^{3}$ & - & 3 \\
Other pathogens & Entamoeba histolytica $^{3}$ & 4 & 5 \\
& Giardia lamblia & 4 & 5 \\
& Campylobacter spp & 2 & 5 \\
& Salmonella spp & 0 & 4 \\
& Candida & 1 & 1 \\
No infective cause & Shigella spp & 1 & 0 \\
& & 24 & 6 \\
\hline
\end{tabular}

*Number in brackets denotes an AIDS diagnosis as a result of finding the pathogen. Numbers in superscript smaller typeface denotes patients with more than one pathogen found.

was diagnosed only if inclusion bodies were seen on the rectal or colonoscopic biopsies.

\section{Results}

MICROBIOLOGICAL RESULTS

In five patients the diagnosis of AIDS was made as a result of an opportunistic infection causing the diarrhoea (Table 1) whereas an opportunistic infection as defined by the $\mathrm{CDC}^{5}$ followed another diagnosis of AIDS in 14 patients. Other potential pathogens were found in 20 AIDS patients and 12 ARC patients. Thus, a third of the ARC patients (12 of 36) had a bacteriological abnormality. Only six patients with AIDS had no potential infectious pathogen in the stool, however, and all of these had other gastrointestinal pathology including oesophageal candidiasis (four), Kaposi's sarcoma (two), squamous carcinoma of the rectum (two). Ten of the 12 patients with Kaposis's sarcoma had stool pathogens as a possible cause of their diarrhoea. More than one potential pathogen was found in seven patients.

\section{CLINICAL FEATURES}

\section{Stool volumes}

These varied considerably from day to day and the diarrhoea ceased in 10 patients initially, but recurred within a few days. In six patients, although more than three liquid motions per day persisted in hospital, the total stool volume was less than $400 \mathrm{cc} / \mathrm{day}$ and in only one of these a potential pathogen was uncovered by stool analysis. The various pathogens responsible for diarrhoea produced variable stool volumes, in excess of $400 \mathrm{cc} /$ day (Table 2). Five patients reported blood and mucus in the stool. This occurred in the three patients with HSV proctitis, one with a solitary rectal 
Table 2 Daily stool volumes and weight loss at presentation in patients with diarrhoea

\begin{tabular}{lrll}
\hline Pathogen & Patients (n) & $\begin{array}{l}\text { Volume average } \\
\text { (range) }\end{array}$ & $\begin{array}{l}\text { Weight loss } \\
\text { average (range) }\end{array}$ \\
\hline MAI & 10 & $500(200-1000)$ & $7(5-12)$ \\
CMV & 6 & $450(200-900)$ & $8(5-12)$ \\
Other pathogen & 35 & $400(100-800)$ & $3(0-5)$ \\
\hline
\end{tabular}

ulcer followed by pseudomembranous colitis, and in the other patient no cause was found.

\section{Abdominal pain}

This was a prominent feature in seven patients and this was most frequently caused by CMV infection (three of seven). Right upper quadrant pain occurred in three of the seven and more generalised abdominal pain in four. The duration of pain varied from between two to six days, was associated in two patients with rebound tenderness and in all resolved spontaneously.

\section{Gross weight loss}

More than $10 \mathrm{~kg}$ weight loss only occurred in those patients with CMV infection or MAI (Table 2). Patients with other opportunistic pathogens and nonopportunistic infection had only lost between $0-5 \mathrm{~kg}$ at the time of presentation. In addition to weight loss over half the patients with MAI infection (six of 10) also had a haemoglobin of less than $10 \mathrm{~g} / \mathrm{dl}$ which was not seen in any other patient group at presentation.

RIGID SIGMOIDOSCOPY AND RECTAL BIOPSY Macroscopic abnormalities were found in 32 of these 81 patients. These changes included severe inflammation like ulcerative colitis (loss of vascular pattern, generalised inflammation and mucosal friability) in 17 and discrete ulceration in four. Eleven patients had a Kaposi's sarcoma of the rectum and two had a squamous carcinoma of the anal canal.

Rectal candidiasis was present in two patients. One patient with a solitary ulcer of the rectum subsequently developed pseudomembranous colitis after a course of antibiotics and two months later ulcerative proctitis as a result of HSV (Table 3 ).

Intestinal spirochaetosis was identified histologically in seven patients. The three AIDS patients all had alternative diagnoses (CMV in two, and HSV in one) although in the four ARC patients no other potential pathogen was identified. In four of the 10 patients with MAI infection numerous organisms were identified within the rectal mucosa.

In the 17 patients with inflammatory proctitis and the four with discrete ulceration acute inflammation was seen histologically. In addition 40 patients had
Table 3 Macroscopic findings at sigmoidoscopy in 81 patients with non-cryptosporidial diarrhoea

\begin{tabular}{|c|c|c|c|}
\hline & Diagnosis & $\begin{array}{l}\text { Abnormality at } \\
\text { sigmoidoscopy } \\
\text { (n) }\end{array}$ & $\begin{array}{l}\text { Total } \\
\text { with the } \\
\text { condition }\end{array}$ \\
\hline \multirow{7}{*}{$\begin{array}{l}\text { Diffuse } \\
\quad \text { inflammation }\end{array}$} & MAI & 4 & 10 \\
\hline & CMV & 3 & 6 \\
\hline & HSV* & 3 & 3 \\
\hline & Campylobacter spp & 2 & 7 \\
\hline & Candida & 2 & 2 \\
\hline & $\begin{array}{l}\text { Pseudomembranous } \\
\text { colitis* }\end{array}$ & 1 & 1 \\
\hline & No pathogen found & 2 & 30 \\
\hline \multirow[t]{2}{*}{ Discrete ulcers } & $\begin{array}{l}\text { Solitary ulcer } \\
\text { syndrome* (typical } \\
\text { histological features) }\end{array}$ & 1 & 1 \\
\hline & $\mathrm{CMV}$ & 3 & 6 \\
\hline \multirow{2}{*}{ Tumours } & KS & 11 & 12 \\
\hline & Squamous carcinoma & 2 & 2 \\
\hline
\end{tabular}

In some patients more than one abnormality was found. *Findings in one patient.

non-specific inflammatory changes, despite a normal sigmoidoscopic appearance, and in half of these a potential pathogen was uncovered.

\section{COLONOSCOPY}

The 81 patients underwent a total colonoscopy in addition to rigid sigmoidoscopy. This provided additional information in only two patients. One had large ulcers in the transverse colon with inclusion bodies typical of CMV histologically. This patient had undergone a barium enema 10 days previously which was reported as normal. A second patient with Kaposi's sarcoma of the skin was found to have a lesion in the transverse colon. Six of the other 11 patients with Kaposi's sarcoma were found to have lesions on colonoscopy in addition to those seen at sigmoidoscopy.

\section{BARIUM ENEMA}

Only 36 patients were willing to have a barium enema in addition to the colonoscopy. This included half the patients with CMV colitis (three of six) and Kaposi's sarcoma (seven of 12) and seven patients with another identified pathogen. Eighteen of these 36 patients had AIDS rather than ARC. Abnormalities seen on the barium enema included Kaposi's sarcoma (three), solitary ulcer (one), fine ulceration of the colon and in the clinical context CMV was suggested as a possible diagnosis (two) and inflammatory proctitis (one). These changes were confirmed by colonoscopy. Six of the 29 patients with a normal barium enema had abnormalities on colonoscopy (Kaposi's sarcoma (four), CMV colitis (two)). The Kaposi's sarcoma lesions that were not seen on barium enema were flat plaque lesions. 


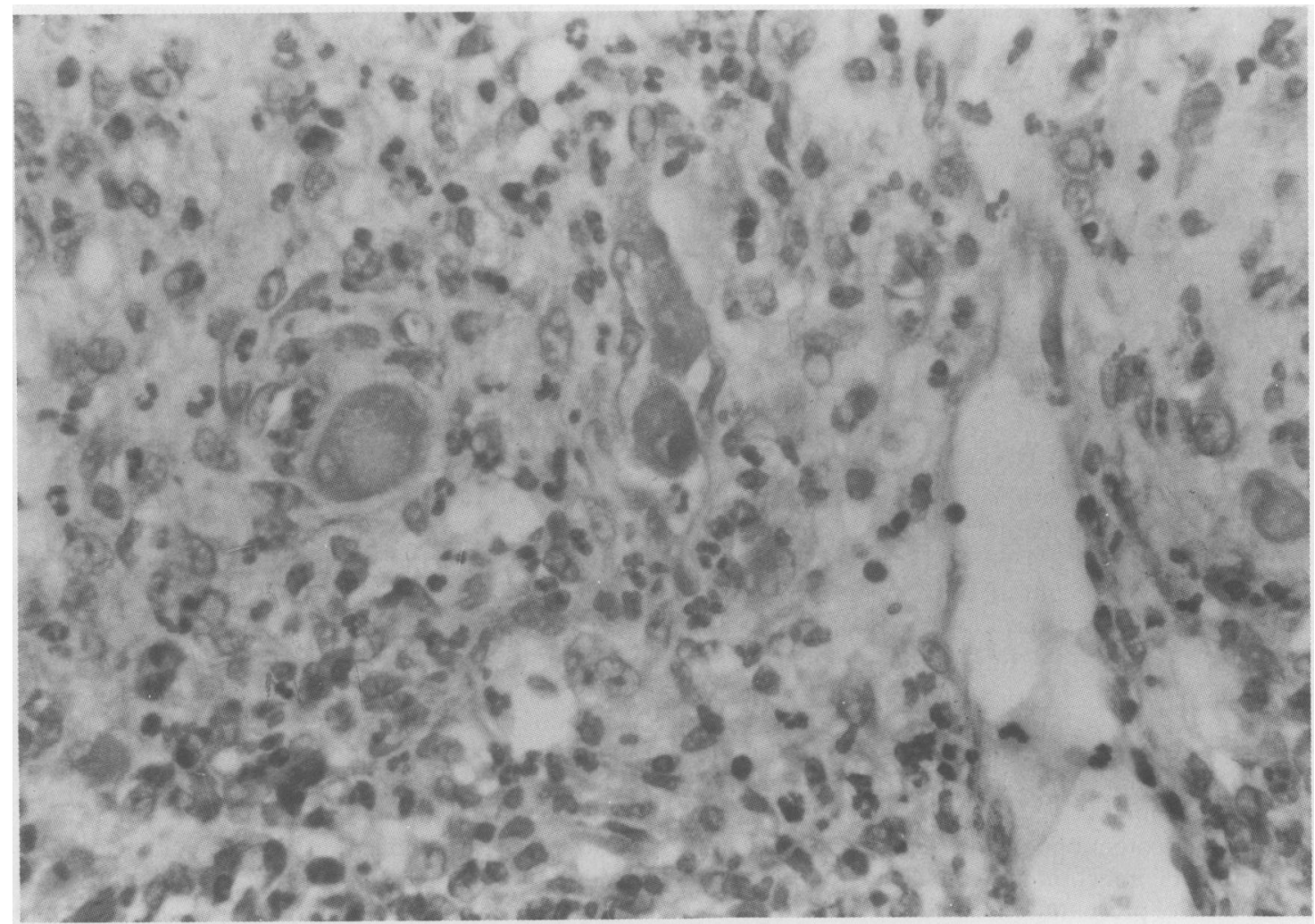

Fig. 1 Section showing inclusions typical of CMV infection in a patient who had a perforated appendix.

ELECTRON MICROSCOPIC STUDIES

In the final 10 patients in whom no pathological cause of the diarrhoea was uncovered multiple rectal biopsies were examined with the electron microscope and in four microtubular structures were seen. Two patients had premalignant changes suggestive of lymphoma which included lipid droplets in the mitochondria, bizarre nuclei, and nuclear pockets. In one of these frank lymphoma of the rectum developed within three months and the other who was diagnosed two months ago is under regular sigmoidoscopic review.

\section{RESULTS OF TREATMENT}

Of the six patients with CMV colitis, two received Foscarnet (phosphonoformate, Astra Pharmaceuticals, compassionate use) in a dose adjusted by the serum creatinine, and two Ganciclovir in a dosage of $2.5 \mathrm{mg} / \mathrm{kg}$, eight hourly iv. The latter two patients had a marked reduction in stool volume, but the two treated with Foscarnet showed no change. Two of the six patients developed a toxic dilatation of the colon which improved spontaneously and one is at present recovering from a perforation of the appendix (Fig. 1). Four of the six patients have died within six months of the diagnosis (Fig. 2). Of the 10 patients with MAI infection all received at least three antituberculous drugs including Ansamycin and Clofazamine but no improvement in stool volumes was noted. Seven of these patients have died (Fig. 2). Three patients with mucocutaneous herpes simplex and diarrhoea have responded to a prolonged course of Acyclovir (200 mg, five times daily).

Treatment of Giardia lamblia (nine patients) with metronidazole $2 \mathrm{~g}$ daily for three days, various salmonella species (four patients) with ampicillin 500 mg qds or campylobacter (seven patients) with some erythromycin $500 \mathrm{mg}$ qds resulted in apparent eradication of these organisms in five patients, but no reduction of stool volume was seen. The stool volumes were not changed in either the nine patients with entamoeba species in the faeces after treatment with Metronidazole $800 \mathrm{mg}$ tds for five days or the seven patients with intestinal spirochaetosis after treatment with penicillin $\mathrm{V}(500 \mathrm{mg}$ qds for three weeks). 


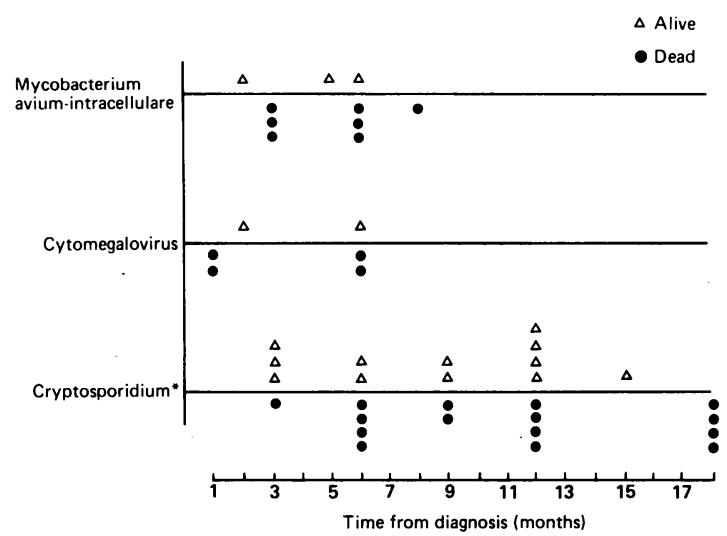

Fig. 2 The length of follow up in live patients $(\triangle)$ and the time to death (O) from diagnosis in patients with CMV colitis, MAI infection or cryptosporidial infection. ${ }^{1}$

\section{Discussion}

We have recently reported our experience with cryptosporidial diarrhoea in AIDS over a five year period. ${ }^{1}$ The capacity to diagnose this organism improved with time and therefore it was decided to undertake a prospective study of diarrhoea in a group of patients who are ill with HIV infection in a unit where hundreds of stool samples from HIV infected individuals have previously been analysed.

Previous studies have emphasised the high proportion of AIDS patients in whom no pathological case of diarrhoea is uncovered. ${ }^{111}$ In contrast this study shows that very few AIDS patients did not have a potential cause of diarrhoea. In contrast, no obvious pathogen was seen in two thirds of the ARC patients. This high proportion may be misleading as five patients were automatically transferred from the ARC to the AIDS category as a result of an opportunist being identified as the cause of the diarrhoea. The high proportion of AIDS patients with a potential pathogen may be due to the large number of stool samples analysed, and the longterm follow up of many patients. An additional reason for the relatively high pick up rate for pathogens would be that we only included patients with persistent diarrhoea and we follow many other patients where the problem is intermittent and would not justify hospital admission. Most pathogens in this study were found after analysis of up to six stool samples, but our previous experience ${ }^{1}$ indicates that cryptosporidium may be more difficult to find, and not surprisingly giardia were frequently missed on initial stool analysis. In addition CMV colitis which depends upon histological demonstration of inclusion bodies may not be diagnosed at the first attempt.
Clinical symptoms were helpful in the diagnosis of CMV colitis as severe abdominal pain was only seen in this group. Massive weight loss, however, was present in MAI and CMV and has previously been noted with cryptosporidial infection. ${ }^{1}$ Likewise in this study the extent of diarrhoea assessed with stool volumes was not helpful diagnostically, although these were significantly less than encountered in our patients with cryptosporidial infection.'

The pathogens found in this study can be divided into two groups. In nine patients CMV or HSV was undoubtedly the cause of the diarrhoea. In other patients, however, the organism discovered was less clearly pathogenic. Patients with MAI infection have previously been divided into three groups: Those in whom colonisation only has occurred, a group with evidence of infection and pathological damage and an intermediate group where evidence was conflicting. ${ }^{3}$ Only four or our patients with MAI had histological evidence of numerous organisms within the mucosa of the gastrointestinal tract and even in these only a mild inflammatory response was seen. Nevertheless these patients were frequently anaemic which we have previously shown to be associated with MAI infection ${ }^{12}$ and had a rapid downhill course and died and in the three who had a post mortem examination the bacterium was found to be widely disseminated in all organs. Unfortunately, although MAI is sensitive in vitro to a variety of antituberculous agents the in vivo response is disappointing $^{3}$ and thus one of the tests of pathogenesis, a response of stool volumes to effective treatment is not available. Similarly, the significance of infection with giardia, salmonella species, and campylobacter is difficult to assess as they were resistant to treatment or there was no response of stool volumes. As salmonella infections are known to relapse frequently in immunosuppressed patients our treatment was probably inadequate as it is now realised that longterm suppressive treatment may be required. ${ }^{2}$ The pathogenesis of various amoeba species in homosexual patients is particularly controversial and as in our patients treatment frequently fails to produce a sustained response. ${ }^{4} \mathrm{We}$ regarded intestinal spirochaetosis as an incidental finding which was not included in the pathogenic causes of diarrhoea. Certainly, penicillin treatment had no effect on stool volumes in these patients and one study has suggested that over one-third of all rectal biopsies taken from homosexuals show this organism. ${ }^{13}$

Although the relationship between a number of potential pathogens and diarrhoea is not clear, it does not seem necessary from our study to invoke other, as yet undiscovered, major causes in this group of patients. 
The microtubular structures seen on electron microscopy of rectal biopsies in a group of patients with no obvious infectious pathogen have previously been associated with HIV infection ${ }^{14}$ is although they also occur in other viral infections and diseases involving immune dysfunction. ${ }^{16}$ Similar structures may be induced by alpha interferon. ${ }^{14}$ Further studies would be needed to see whether these structures correlate with the finding of HIV infection in the gut by DNA hybridisation as recently described. ${ }^{17}$ The case for HIV infection itself causing diarrhoea or malabsorption might be strengthened if microtubular structures or evidence of infection by DNA hybridisation were found in the patients with diarrhoea in whom no other pathogen was found rather than in AIDS patients without diarrhoea or in those in whom other pathogens which can cause diarrhoea were uncovered.

Very few patients in this study had Kaposi's sarcoma of the gut as a likely cause of diarrhoea. Although visceral spread has occurred in 40 of our 102 patients with Kaposi's sarcoma only 12 patients in this study with gut Kaposi's had diarrhoea and in only two was there no other potential pathogen present in the stool.

Total colonoscopy yielded very little extra information compared with simple rigid sigmoidoscopy and rectal biopsy and is not recommended in routine evaluation of these patients. Likewise, barium enema had a low diagnostic yield.

We would recommend analysis of multiple stool samples, rigid sigmoidoscopy and rectal biopsy as the procedure of choice in routine clinical practice and that other investigations should be reserved for the small number of more difficult patients.

We wish to thank Dr D S Ellis and Mr G Tovey, Electron Microscopy Laboratory, London School of Hygeine and Tropical Medicine, Keppel Street (Gower Street), London WC1E 7HT. The laboratory staff at St Stephen's Hospital, Fulham Road, SW10, in particular Miss Jenny Midgeley, Chief Technician, Department of Microbiology. The patients and staff of Thomas Macaulay Ward, St Stephen's Hospital. Lastly we would like to thank Miss Coralie Armstrong and Miss Linda Stannard for their secretarial assistance.

\section{References}

1 Connolly GM, Dryden MS, Shanson DC, Gazzard BG. Cryptosporidial diarrhoea in AIDS and its treatment. Gut 1988; 29: 593-7.
2 Jacobs JL, Gold JWM, Murray HW, et al. Salmonella infections in patients with the acquired immunodeficiency syndrome. Ann Intern Med 1985; 102: 186-8.

3 Hawkins CC, Gold JWM, Whimbey E, et al. Mycobacterium avium complex infections in patients with the acquired immunodeficiency syndrome. Ann Intern Med 1986; 105: 184-8.

4 Quinn TC, Stamm WE, Goodell SE, et al. The polymicrobial origin of intestinal infections in homosexual men. N Engl J Med 1983; 309: 576-82.

5 Centres for disease control. Revision of the CDC surveillance case definition for acquired immunodeficiency syndrome. $M M W R$ 1987; 36 [Suppl]: No 1S.

6 Wellcome Diagnostics. Wellcozyme anti-HTLV III. (Enzyme immunoassay for detection of antibody to Human $T$ cell lymphotropic type III [HTLV III] Lymphadenopathy virus [LAV]. Beckenham, Kent: Wellcome, 1987.

7 Mortimer PP, Parry JV, Mortimer JY. Which antiHTLV III/LAV assays for screening and confirmation testing? Lancet 1985; ii: 873-7.

8 Garcia LS, Bruckner DA, Brewer TC, Shimizu RY. Techniques for the recovery and identification of cryptosporidium oocysts from stool specimens. J Clin Microbiol 1983; 18: 185-90.

9 Mitchison DA, et al. Selective kirchner medium in the culture of specimens other than sputum for mycobacteria. J Clin Pathol 1983; 36: 1357-61.

10 Kotler DP, Gaetz HP, Lange M, Klein EB, Holt PR. Enteropathy associated with the acquired immunodeficiency syndrome. Ann Intern Med 1984; $101 \%$ 421-8.

11 Gillin JS, Shike M, Alcock N, et al. Malabsorption and mucosal abnormalities of the small intestine in the acquired immune deficiency syndrome. Ann Intern Med 1985; 102: 619-22.

12 Gardener TD, Flanagan P, Dryden MS, Costello C, Shanson DC, Gazzard BG. Disseminated mycobacterium avium-intracellulare infection and red cell hypoplasia in patients with the acquired immunodeficiency syndrome. J Infect 1988; 16: 135-40.

13 McMillan A, Lee FD. Sigmoidoscopic and microscopic appearance of the rectal mucosa in homosexual men. Gut 1981; 22: 1035-41.

14 Sidhu GS, Stahl RE, El-Sadr W, Zolla-Pazner S. Ultrastructural markers of AIDS. Lancet 1983; i: 990-1.

15 Dobbins WO, Weinstein WM. Electron microscopy of the intestine and rectum in acquired immunodeficiency syndrome. Gastroenterology 1985; 88: 738-49.

16 Grimley PM, Schaff ZS. Significance of tubuloreticular inclusions in the pathobiology of human diseases. In: Inochim HL, ed. Pathobiology annual. New York: Appleton-Century Crofts, 1976: 221-57.

17 Nelson JA, Wiley CA, Reynolds-Kohler C, Reese CE, Margaretten W, Levy JA. Human immunodeficiency virus detected in bowel epithelium from patients with gastrointestinal symptoms. Lancet 1988 i: 259-62. 